\title{
LA RECIENTE CONSTITUCIONALIZACIÓN DE LA ESTABILIDAD PRESUPUESTARIA: ¿UNA REFORMA NECESARIA?
}

DAVID DELGADO RAMOS 
SUMARIO

1. INTRODUCCIÓN. 2. POMPA Y CIRCUNSTANCIA DE UNA REFORMA EXPRÉS. 3. MARCO NORMATIVO: 3.1 Marco jurídico-constitucional. 3.2 Antecedentes: la Ley General de Estabilidad Presupuestaria de 2001. 3.3 La sentencia del Tribunal Constitucional de 20 de julio de 2011. 4. EL PROCESO DE REFORMA: 4.1 El Acuerdo Político PP-PSOE y la Proposición de Ley de Reforma. 4.2 El procedimiento parlamentario. 4.3 El trámite de enmiendas en el Congreso y el Senado. 4.4 El recurso de amparo ante el Tribunal Constitucional de dos diputados del Grupo Parlamentario de ERC-IU-ICV. 4.5 El polémico debate sobre la necesidad de un referéndum consultivo. 5. CONCLUSIONES: ¿ERA NECESARIA UNA REFORMA CONSTITUCIONAL? 


\title{
LA RECIENTE CONSTITUCIONALIZACIÓN DE LA ESTABILIDAD PRESUPUESTARIA: ¿UNA REFORMA NECESARIA?
}

\author{
DAVID DELGADO RAMOS ${ }^{1}$
}

\section{INTRODUCCIÓN}

El martes 23 de agosto de $2011^{2}$, con ocasión del debate sobre la convalidación del Real Decreto-ley 9/2011, de 19 de agosto, de medidas para la mejora de la calidad y cohesión del Sistema Nacional de Salud, de contribución a la consolidación fiscal, y de elevación del importe máximo de los avales del Estado para 2011, el presidente del Gobierno, José Luis Rodríguez Zapatero, sugirió inesperadamente la posibilidad de proceder a una reforma constitucional para tratar de «establecer una regla para garantizar la estabilidad presupuestaria en el medio y largo plazo en relación tanto con el déficit estructural como con la deuda, que vinculara a todas las administraciones públicas».

La estabilidad presupuestaria, sostenía el presidente del Gobierno en su intervención, debiera quedar recogida en la Constitución por ser una «decisión estratégica de calado, estructural y no coyuntural, y muy mayoritariamente asumida por la sociedad española y por sus representantes», por lo que sugería el mayor consenso posible para efectuar la reforma constitucional, para lo que invitó a «los dos gru-

1 Doctorando en Derecho Constitucional, UCM.

2 Hay que anotar, como dato marco, que tan sólo siete días antes, el 16 de agosto, cuando el euro se encontraba seriamente amenazado por la crisis de deuda, se había celebrado una trascendental cumbre franco-alemana entre Merkel y Sarkozy en la que anunciaron la intención de crear «un verdadero Gobierno económico europeo» que sirviese para devolver «la confianza en los mercados». 
pos mayoritarios y a los demás grupos de la Cámara a que lo concreten en una proposición de ley de reforma que pudiera ser aprobada de inmediato».

Pese a la sorpresa que generó en todo el arco parlamentario, por inesperada ${ }^{3}$ en los estertores de una legislatura, a poco más de un mes de la disolución anticipada de las Cortes y la subsiguiente convocatoria electoral para el domingo veinte de noviembre, el guante fue recogido inmediatamente por el jefe de la oposición y líder del Partido Popular y, con ambages, por el candidato socialista a la Presidencia del Gobierno, Alfredo Pérez Rubalcaba ${ }^{4}$.

Por ello, pese a las fuertes reticencias que en el seno del Partido Socialista generó la iniciativa del Presidente del Gobierno ${ }^{5}$, la necesidad de un consenso político que permitiera garantizar la disciplina presupuestaria con independencia del partido político que tuviese la responsabilidad de Gobierno favoreció el acuerdo político entre el Partido Socialista y el Partido Popular, acuerdo al que no se sumaron el resto de formaciones políticas al considerar que habían sido excluidas del proceso de reforma constitucional, o bien porque discrepaban profundamente del sentido de la reforma propuesta.

En cualquier caso, desde un punto de vista estrictamente jurídico, esta reforma constitucional, la segunda que se produce en nuestro país en los casi treinta y cinco años de efectiva vigencia de la Constitución ${ }^{6}$, exige una cautelosa

3 De lo inesperado del anuncio da buena cuenta el hecho de que tanto Alfredo Pérez Rubalcaba como Mariano Rajoy fueron informados la noche antes del Pleno del Congreso por el Presidente.

4 El presidente del Gobierno no consultó con Alfredo Pérez Rubalcaba, como hubiese sido lo lógico teniendo en cuenta que era el candidato del PSOE a la Presidencia del Gobierno para las Elecciones Generales de otoño, la reforma constitucional para incluir la estabilidad presupuestaria. El candidato socialista, visiblemente sorprendido por el anuncio de reforma de la Constitución, y contrario a ella hasta ese momento, salió al paso declarando que «Zapatero me convenció de la reforma constitucional anoche, tras pactar con Rajoy». Poco después, en una entrevista en el diario EL PAÍS (11/09/2011), consciente de que de cara su electorado más profundamente de izquierdas dicha reforma le ocasionaba un problema político de calado, justificará su apoyo diciendo que él "babría hecho la reforma (constitucional) distinta que Zapatero y que Rajoy», señalando además que sus reticencias «nacían fundamentalmente del propio procedimiento de abrir la Constitución probablemente de una forma poco elaborada». Según él, dio su apoyo final a la reforma por el "principio de responsabilidad».

5 Una gran parte del PSOE se mostró en contra de la propuesta de reforma por entender que era contraria a los principios y valores socialistas y porque suponía la quiebra del Estado del Bienestar al constitucionalizar la estabilidad presupuestaria, un aparente pilar básico del neoliberalismo.

6 La primera, como es sabido, se produjo en 1992 con ocasión de la ratificación del Tratado de Maastricht para permitir que cualquier ciudadano de la Unión Europea que residiese en otro Estado de la Unión distinto al suyo pudiese ser elector y elegido en las elecciones municipales de 
reflexión para analizar la necesidad de una reforma que, aún tímida, no deja de ser una reforma constitucional que, consagrada, otorga en puridad la mayor fuerza vinculante a la limitación presupuestaria del déficit no sólo para el Estado sino, como es natural, para las comunidades autónomas y las entidades locales, el auténtico problema financiero para el control del déficit público español.

\section{POMPA Y CIRCUNSTANCIA DE UNA REFORMA EXPRÉS}

Pese a la sorpresa generada por el anuncio del presidente del Gobierno de instar al acuerdo para promover una reforma constitucional con objeto de introducir el principio de estabilidad presupuestaria, la propuesta no sólo no era novedosa, sino que ya fue solicitada por el entonces jefe de la oposición y líder del Partido Popular, Mariano Rajoy, en junio de $2010^{7}$.

En aquel momento, tras las duras medidas de ajuste presupuestario anunciadas por el presidente del Gobierno en mayo de $2010^{8}$, la propuesta fue des-

dicho Estado. La reforma, que gozó de un amplísimo consenso, modificó el artículo 13.2 de la Constitución.

7 El 25 de junio de 2010, en una intervención en el Foro Nueva Economía, sostuvo que promovería un consenso político en España para que la Constitución recogiese los principios de la estabilidad presupuestaria, «algo parecido» a lo que ya ha hecho Alemania. Además, consideró «imprescindible» una nueva normativa de disciplina presupuestaria que estableciese techos de gasto y de endeudamiento de todas las Administraciones e insistió en que no era posible recortar el gasto público sin reformas institucionales profundas que evitasen duplicidades, porque «si todos hacen de todo, no se usan bien los recursos, y éstos son abora escasos».

8 El presidente del Gobierno anunció el 12 de mayo de 2010, ante el Pleno del Congreso, que ante la gravedad de la crisis griega y los riesgos que se cernían sobre España, el Gobierno se veía obligado a un mayor esfuerzo de austeridad: «el Gobierno ha decidido: reducir las retribuciones del personal del sector público en un 5 por ciento de media a partir de junio de 2010 y congelarlas en 2011; los miembros del Gobierno y los demás altos cargos tendrán una reducción superior al último tramo de la escala que se establezca para los empleados públicos. Suspender para 2011 la revalorización de las pensiones, excluyendo las no contributivas y las pensiones mínimas. Eliminar el régimen transitorio para la jubilación parcial previsto en la Ley 40/2007. Eliminar la prestación por nacimiento de 2.500 euros a partir del 1 de enero de 2011. Reducir los gastos en farmacia mediante una revisión del precio de los medicamentos excluidos del sistema de precios de referencia y mediante la adecuación del número de unidades de los envases de los medicamentos a la duración estandarizada de los tratamientos, así como dispensación de medicamentos en unidosis. Suprimir para los nuevos solicitantes la retroactividad del pago de prestaciones por dependencia el día de presentación de la solicitud, estableciéndose paralelamente un plazo máximo de resolución de seis meses cuyo incumplimiento llevará aparejada retroactividad desde esa fecha. Se dispone asimismo una reducción entre 2010 y 2011 de 600 millones de euros en la ayuda oficial al desarrollo. Se prevé una reducción de 6.045 millones de euros entre 2010 y 2011 en la inversión pública estatal y se prevé un aborro adicional de 1.200 millones de euros por parte de las comunidades autónomas y las entidades locales». Estas medidas fueron aprobadas en el Consejo de Ministros del 20 de mayo y recogidas 
estimada irónicamente tanto por el entonces ministro del Interior y candidato socialista a la Presidencia del Gobierno, Alfredo Pérez Rubalcaba9 ${ }^{9}$, como por la vicepresidenta del Gobierno para Asuntos Económicos, Elena Salgado ${ }^{10}$, y hasta por el propio presidente del Gobierno, José Luis Rodríguez Zapatero ${ }^{11}$.

El cambio de opinión se produjo como consecuencia de las graves tensiones económicas que, particularmente en agosto de 2011, estaba sufriendo la economía española en su financiación exterior y que habían desatado una oleada especulativa con el bono español, cuya prima de riesgo ${ }^{12}$ llegó a superar los cuatrocientos puntos básicos ${ }^{13}$. Esta vorágine especulativa hacía peligrar no sólo nuestra capacidad de financiación, sino que, aún más grave, acercaba al país a la peligrosa

en el Real Decreto-ley 8/2010, de 20 de mayo, por el que se adoptan medidas extraordinarias para la reducción del déficit público.

9 Al día siguiente de las declaraciones de Mariano Rajoy, el 26 de junio, Alfredo Pérez Rubalcaba afirmó, en un discurso en la Convención Municipal de los Socialistas de Mallorca que «Como todos sabemos, la Constitución es una ley que se cambia fácilmente y en un plis-plas nos arregla la crisis».

10 El 28 de octubre, en el Foro Cinco Días, insistió en que limitar por ley el gasto de las comunidades autónomas «no cabe en la Constitución» y no tendría sentido reformarla «sólo para eso».

11 El 14 de julio, con ocasión del Debate sobre el Estado de la Nación, y en su turno de réplica a Mariano Rajoy, declaró con sarcasmo —en referencia a la modificación constitucional propuesta por el líder del PP_ que «babia una medida original, la habia, fue la que más eco tuvo, que era reformar la Constitución para impedir el déficit. Una reforma que, como saben, es rápida, dado cómo es nuestro procedimiento de reforma constitucional, y que sería muy eficaz para combatir la coyuntura de la crisis económica. Esa ha sido toda la reforma original que le hemos oído en los últimos meses y que no tiene ni fundamento, ni eficacia, ni capacidad».

12 La prima de riesgo es el sobreprecio pagado por el bono de un país con respecto del bono alemán a diez años. Se utiliza el bono alemán porque es considerado el título de Deuda Pública más «fiable» o seguro de toda la Unión Europea y, por lo tanto, el menos volátil ante cualquier coyuntura económica. Por ello, se considera que la prima de riesgo o riesgo-país es un factor que mide la «confianza» de los mercados internacionales en la economía de un Estado y, particularmente, en su solvencia financiera.

13 Como muestra de lo que supone en términos económicos para España una prima de riesgo tan elevada, el presidente del BBVA, Francisco González, señaló que 100 puntos básicos de incremento de la prima de riesgo implican para España un coste extra de financiación de 12.400 millones de euros anuales, cantidad que equivale a un 1,2\% del PIB, lo que permitiría financiar con creces las inversiones en infraestructuras de 8.400 millones de euros previstas para 2011 y la creación de 160.000 empleos. Es decir, el alza de tan solo un punto básico supone alrededor de 120 millones de euros de coste adicional en nuestra financiación. Como muestra de la gravedad, recordar que Grecia fue intervenida cuando su prima de riesgo alcanzó los 965 puntos básicos y el tipo de interés del bono griego a 10 años superó el 12,4\%. Irlanda, cuando su prima de riesgo alcanzaba los 544 puntos básicos y el tipo de interés del bono a 10 años estaba en $8,09 \%$ y Portugal, cuando su prima de riesgo estaba en 517,6 puntos y se pagaba un $8,59 \%$ de interés por su bono a 10 años. 
estela de la intervención internacional —el temido «rescate»—, por parte de la Unión Europea y el Fondo Monetario Internacional que ya habían sufrido Grecia, Irlanda y Portugal ${ }^{14}$.

La tensión especulativa con el bono español, de extraordinaria virulencia, causó una enorme inquietud en la Unión Europea, preocupada por una escalada en la prima de riesgo española que parecía, con fuertes oscilaciones, no tener fin, y que amenazaba la estabilidad económica europea.

Hay que recordar que España, en su condición de país periférico y de economía más débil y menos industrializada que la de Alemania, Francia o Reino Unido, representa una fuente de gran incertidumbre económica para nuestros socios europeos porque es considerada, por su población, un socio de tamaño «medio»: es el país más grande de los «medianos», junto con Polonia, pero no alcanza la relevancia político-económica de los llamados «grandes», encabezados por Alemania, Francia y Reino Unido. Lo suficientemente grande como para no ser considerado pequeño, pero lo suficientemente pequeño como para no ser considerado grande.

Esta cuestión, más allá de una mera cuestión poblacional, condiciona, en esta crisis de deuda, el rol político que juega la economía española en el tablero europeo. España representa como país un riesgo mucho más elevado del que han representado Grecia, Irlanda y Portugal juntas, que son, en el contexto europeo, economías poco relevantes. El tamaño y la importancia económica de España, en cambio, dificultan enormemente un hipotético «rescate» por parte de la Unión Europea y el Fondo Monetario Internacional.

De ahí la constante vigilancia de nuestros socios europeos sobre la economía española y la permanente exigencia de reformas estructurales, agravada, además, por el temor a un posible «efecto contagio» o «efecto dominó» sobre la mayor economía de la periferia de la Unión Europea, Italia, el verdadero problema por su tamaño y su extraordinaria Deuda Pública ${ }^{15}$.

14 Grecia solicitó el «rescate» económico internacional el 2 de mayo de 2010, mientras que Irlanda lo hizo el 22 de noviembre de 2010 y Portugal el 7 de abril de 2011. El desembolso efectuado por los rescates, sujeto a unos severísimos y supervisados planes de ajuste presupuestario, fue de 268.000 millones de euros para Grecia (110.000 millones de euros del primer rescate, de mayo de 2010, y 158.000 millones de euros del segundo rescate, de julio de 2011), 85.000 millones para Irlanda y 78.000 millones para Portugal.

15 La paradoja italiana es que si bien su déficit público es bajo en comparación con otros países — del 4,6\% según los últimos datos disponibles de 2011, frente al 8,2\% español o el 7,1\% de Francia-, su Deuda Pública es del 120\% (1,8 billones de euros), frente a un $61 \%$ de la española o un $82,3 \%$ de la francesa o incluso del $83,2 \%$ de la alemana. Italia es el tercer país del mundo que más Deuda Pública tiene en circulación en los mercados tras Estados Unidos y Japón. 
En estas circunstancias, y ante el cariz que estaban tomando los acontecimientos, en los que la tensión especulativa, lejos de amainar, arreciaba, la máxima autoridad monetaria europea, el Banco Central Europeo, decidió, con objeto de reducir la presión de los mercados internacionales, realizar comprar masivas de títulos de deuda pública de España e Italia.

A cambio, y según se conoció después ${ }^{16}$, se exigía a España que siguiese por la senda de las reformas estructurales que había iniciado en mayo de 2010 y que tenían por objeto la reducción del déficit, primero al $6 \%$ a finales de 2011 , pero cuyo objetivo último era alcanzar el $3 \%$ a finales de $2012^{17}$. Un objetivo muy difícil de alcanzar en tiempo y forma y que estaba requiriendo de extraordinarios ajustes presupuestarios para controlar un gasto público que se había desbocado en los últimos años, particularmente en las comunidades autónomas y las entidades locales. Un gasto público autonómico y local que, además, sólo empezó a reducirse de manera significativa tras las Elecciones autonómicas y municipales del 22 de mayo, pero que lejos de relajar la presión y las dudas sobre nuestra economía las agravó, al ser reveladas grandes ineficiencias en la gestión presupuestaria de algunas comunidades autónomas y un uso de los fondos públicos desviado en muchos casos de la más elemental ortodoxia presupuestaria.

\section{MARCO NORMATIVO}

\subsection{Marco jurídico-constitucional}

La reforma operada, desde el primer momento, quedó claro que se produciría en el Título VII de la Constitución, Economía y Hacienda, por ser el más adecuado al objetivo pretendido con la reforma constitucional.

16 Es la célebre «carta» que el presidente del Banco Central Europeo, Jean-Claude Trichet, envió al presidente del Gobierno español a principios del mes de agosto de 2011 exigiéndole más reformas a cambio de continuar con las compras que el BCE estaba realizando de la Deuda Pública española para frenar la escalada especulativa con el bono español, que había llevado la prima de riesgo a límites insostenibles. La existencia de la carta, no difundida por el Gobierno, fue reconocida tras las elecciones generales por el nuevo Gobierno.

17 Tal y como recoge el Programa de Estabilidad 2011-2014, España se comprometió a «alcanzar un déficit del 3\% del PIB en 2013 y del 2,1\% en 2014. Para ello, los objetivos presupuestarios intermedios son: déficit de 9,3\% del PIB en 2010, de 6\% en 2011 y de 4,4\% en 2012». En términos económicos se estima que cada punto del déficit que se recorta son unos 10.000 millones de euros, por lo que el ajuste del gasto debiera haber sido en dos años, con independencia de quien hubiere resultado vencedor de las elecciones generales, de 30.000 millones de euros. 
Aunque en un primer momento se planteó la posibilidad de modificar el artículo $134^{18}$, relativo a los Presupuestos Generales del Estado, al quedar éstos limitados en su elaboración por la futura reforma, fue finalmente modificado el artículo $135^{19}$, por ser éste más acorde al sentido de la modificación constitucional al tratar de la Deuda Pública y el endeudamiento del Estado, sobre todo, teniendo en cuenta la competencia exclusiva que el artículo 149.1.14 de la Constitución establece a favor del Estado en lo referido a «Hacienda general y Deuda del Estado».

El artículo 135 que se encontraba en vigor, desde un punto de vista constitucional, era un artículo que no tenía paragón en las constituciones de nuestro entorno, pues no lo contemplaban ni la Ley Fundamental de Bonn, ni las constituciones italiana y francesa. Sin embargo, su contenido, paradójicamente, puede ser considerado un «clásico» de nuestra historia constitucional al estar recogido en todas nuestras constituciones desde $1812^{20}$.

18 Artículo 134 de la Constitución:

«1. Corresponde al Gobierno la elaboración de los Presupuestos Generales del Estado y a las Cortes Generales su examen, enmienda y aprobación.

2. Los Presupuestos Generales del Estado tendrán carácter anual, incluirán la totalidad de los gastos e ingresos del sector público estatal y en ellos se consignará el importe de los beneficios fiscales que afecten a los tributos del Estado.

3. El Gobierno deberá presentar ante el Congreso de los Diputados los Presupuestos Generales del Estado al menos tres meses antes de la expiración de los del año anterior.

4. Si la Ley de Presupuestos no se aprobara antes del primer día del ejercicio económico correspondiente, se considerarán automáticamente prorrogados los Presupuestos del ejercicio anterior hasta la aprobación de los nuevos.

5. Aprobados los Presupuestos Generales del Estado, el Gobierno podrá presentar proyectos de ley que impliquen aumento del gasto público o disminución de los ingresos correspondientes al mismo ejercicio presupuestario.

6. Toda proposición o enmienda que suponga aumento de los créditos o disminución de los ingresos presupuestarios requerirá la conformidad del Gobierno para su tramitación.

7. La Ley de Presupuestos no puede crear tributos. Podrá modificarlos cuando una ley tributaria sustantiva así lo prevea.»

19 El artículo 135, antes de la reforma, decía lo siguiente:

«1. El Gobierno habrá de estar autorizado por ley para emitir Deuda Pública o contraer crédito.

2. Los créditos para satisfacer el pago de intereses y capital de la Deuda Pública del Estado se entenderán siempre incluidos en el estado de gastos de los presupuestos y no podrán ser objeto de enmienda o modificación, mientras se ajusten a las condiciones de la ley de emisión.»

20 Artículo 355 de la Constitución Española de 1812: «La Deuda Pública reconocida será una de las primeras atenciones de las Cortes, y éstas pondrán el mayor cuidado en que se vayan verificando su progresiva extinción, y siempre el pago de los réditos en la parte que los devengue, arreglando todo lo concer- 
El artículo contenía «los tres principios que caracterizan el instituto de endeudamiento público: es un ingreso público, su régimen esencial debe regularse por ley y, en fin, su fundamento se encuentra en la capacidad que el Estado tiene para generar confianza en los prestamistas; en su solvencia económica, en definitiva» ${ }^{21}$.

Con todo, su contenido, en lo que respecta al endeudamiento público, no contenía limitaciones materiales, sino tan solo puramente formales ${ }^{22}$, lo que impedía en la práctica la garantía de su efectivo cumplimiento, puesto que tan solo recorría el ciclo de la Deuda pública ${ }^{23}$. Era, tanto en su punto primero, relativo a la autorización que deberá tener el Gobierno para emitir Deuda pública, como en su punto segundo, concerniente a la inclusión como gasto presupuestario de los créditos para el pago de los intereses y el capital, un artículo de escaso recorrido material puesto que no impedía o dificultaba un uso indebido o excesivo

niente a la dirección de este importante ramo, tanto respecto a los arbitrios que se establecieren, los cuales se manejarán con absoluta separación de la tesorería general, como respecto a las oficinas de cuenta y razón».

Artículo 75 de la Constitución de 1837: «La Deuda Pública está bajo la salvaguardia especial de la nación».

Artículo 78 de la Constitución de 1845: «La Deuda Pública está bajo la salvaguardia de la nación».

Artículo 104 de la Constitución de 1869: «La Deuda Pública está bajo la salvaguardia especial de la nación. No se hará ningún empréstito sin que se voten antes los recursos necesarios para pagar sus intereses».

Artículo 87 de la Constitución de 1876: «La Deuda Pública está bajo la salvaguardia de la nación».

Artículo 118 de la Constitución de 1931: «La Deuda Pública está bajo la salvaguardia del Estado. Los créditos necesarios para satisfacer el pago de intereses y capitales se entenderán siempre incluidos en el estado de gastos del presupuesto y no podrán ser objeto de discusión mientras se ajusten estrictamente a las leyes que autorizaron la emisión. De idénticas garantías disfrutará, en general, toda operación que implique, directa o indirectamente, responsabilidad económica del Tesoro, siempre que se dé el mismo supuesto».

21 TEJERIZO LÓPEZ, Manuel. «Comentario al Artículo 135», en ALZAGA VILLAAMIL, Óscar, Comentarios a la Constitución Española de 1978, Cortes Generales-Editoriales de Derecho Reunidas, Madrid, 1996, pág. 347.

22 "A diferencia de otras Constituciones extranjeras, no contiene ningún límite material para la apelación al endeudamiento público, siendo los principios que contiene el artículo 135 puramente formales, en tanto se dirigen a ordenar la distribución de competencias entre el poder legislativo y el poder ejecutivo». DE LA HUCHA CELADOR, Fernando, «Comentario al Artículo 135 de la Constitución», en CASAS BAAMONDE, María Emilia y RODRÍGUEZ-PIÑERO Y BRAVO-FERRER, Miguel, Comentarios a la Constitución Española, Fundación Wolters Kluwer, Madrid, 2009, pág. 2049.

23 «El apartado 2 del artículo 135 completa lo que podría llamarse ciclo de la Deuda Pública, dado que si el apartado 1 del mismo disciplina su emisión, el apartado 2 contempla su reembolso». CAZORLA PRIETO, Luis M. ${ }^{a}$, «Comentario al Artículo 135 de la Constitución», en GARRIDO FALLA, Manuel (coordinador), Comentarios a la Constitución, Madrid, Civitas, 1985, pág. 2054. 
del recurso al endeudamiento público, sino tan solo su uso por vías no legales y, por lo tanto, no emanadas de las Cortes.

En cualquier caso, hay que señalar que aun teniendo la autorización del Parlamento, el Gobierno no se encontraba obligado a emitir el volumen máximo de endeudamiento autorizado, sino que la autorización era «una limitación cuantitativa que no puede sobrepasar» ${ }^{24}$. Es decir, la autorización implicaba un «techo» de endeudamiento, por lo que el Gobierno podía, conforme a su criterio, no ejecutarlo en su totalidad.

En lo que respecta al alcance del derogado artículo 135, y pese a que fue discutido por la doctrina ${ }^{25}$, se consideraba mayoritariamente que afectaba no sólo al Estado como Administración Central y a sus entes y organismos dependientes, sino también a las comunidades autónomas y a las entidades locales. Hay que recordar que, pese a que las comunidades autónomas pueden endeudarse, dicho endeudamiento debe ser autorizado por el Estado.

Por último, huelga decir, quizá por obvio, que la reforma constitucional se ha operado al albur del artículo 167, toda vez que el artículo modificado no constituye una reforma agravada de la Constitución, con toda la complejidad jurídica que ello requeriría. Una cuestión importante políticamente pues, en

24 DE LA HUCHA CELADOR, Fernando, «Comentario al Artículo 135 de la Constitución», op. cit., pág. 2052.

25 En este punto, la mayoría de la doctrina, encabezada por autores como De La Hucha Celador sostiene que el artículo 135 se trataba de un «principio general del ordenamiento constitucional, aplicable a los distintos niveles de organización territorial del Estado». DE LA HUCHA CELADOR, Fernando, «Comentario al Artículo 135 de la Constitución», op. cit., pág. 2054. Otros, muy minoritarios, como Tejerizo López, sostenían en cambio que «En el artículo 135 la Constitución se refiere únicamente a la Deuda pública emitida por la Administración estatal. Varios son los argumentos que avalan esta postura:

a) En primer lugar, la mención al Gobierno como destinatario del mandato establecido en el apartado primero. En sede constitucional la expresión Gobierno, sin ningún calificativo añadido, tiene que entenderse en sentido estricto, es decir, referida al órgano colegiado que culmina la organización de la Administración del Estado y cuya composición se establece en el artículo 98.1 de la propia Constitución.

b) La alusión a los Presupuestos que realiza el artículo debe entenderse referida a los estatales. No sólo porque se relaciona con la Deuda pública del Estado, sino también porque son únicamente los presupuestos del Estado los que se regulan en el Título donde se encuentra el precepto estudiado. Esta es la opinión que sostiene el Tribunal Constitucional en las sentencias 116/1994, de 18 de abril, y 149/1994, de 12 de mayo.

c) Aquí no parece tener justificación lógica la referencia a la Deuda pública de las Administraciones territoriales distintas del Estado, porque ya se alude a ellas en otros preceptos constitucionales: a la Deuda pública local, aunque de modo tácito, en el artículo 142, y a la Deuda de las Comunidades Autónomas en el artículo 157.»

TEJERIZO LÓPEZ, Manuel, «Comentario al Artículo 135», op. cit., pág. 355. 
caso de haber requerido una reforma del artículo 168, ésta, por motivos de oportunidad política, muy probablemente no se hubiese producido.

\subsection{Antecedentes: la Ley General de Estabilidad Presupuestaria de 2001}

Sin embargo, la cuestión jurídica no se queda en la Constitución. Aunque se ha revestido con una pátina de constitucionalidad para consagrar su importancia y garantizar su cumplimiento, la existencia de una regulación jurídica de la estabilidad presupuestaría existía hasta no hace mucho tiempo: la Ley General de Estabilidad Presupuestaria de 2001.

En el año 2001, el Gobierno decidió elaborar una Ley General de Estabilidad Presupuestaria al considerar, tal y como se recogía en la propia exposición de motivos de la Ley 18/2001, de 12 de diciembre, General de Estabilidad Presupuestaria, que «el equilibrio presupuestario va a ser la gran contribución de la política presupuestaria a la estabilidad macroeconómica que posibilita seguir desarrollando el verdadero potencial de crecimiento y de generación de empleo de la economía española y con ello avanzar en el proceso de convergencia real con los países más desarrollados».

La Ley, además, consagraba jurídicamente lo establecido en el Pacto de Estabilidad y Crecimiento, acordado en el Consejo de Ámsterdam en junio de 1997 que, como oportunamente se recordaba en la exposición de motivos, "limita la utilización del déficit público como instrumento de política económica de la Unión Económica y Monetaria. En virtud del referido Pacto, los Estados miembros de la Unión se comprometen a perseguir el objetivo a medio plazo de situaciones presupuestarias próximas al equilibrio o en superávit, de forma que, cuando los estabilizadores automáticos actúen, el déficit se mantenga siempre por debajo del $3 \%$.».

La Ley, además, proclamaba su carácter básico a tenor de lo dispuesto en los artículos 149.1 .13 y 18 de la Constitución ${ }^{26}$, por lo que resultaba de aplicación al conjunto de las Administraciones Públicas, estableciendo así por vez primera una disciplina presupuestaria de obligado cumplimiento.

Desde un punto de vista jurídico, la ley definió la estabilidad presupuestaria, en su artículo 3, como «se entenderá por estabilidad presupuestaria la situación de

26 Artículo 149 de la Constitución:

«13." Bases y coordinación de la planificación general de la actividad económica.

18. Las bases del régimen jurídico de las Administraciones públicas y del régimen estatutario de sus funcionarios que, en todo caso, garantizarán a los administrados un tratamiento común ante ellas; el procedimiento administrativo común, sin perjuicio de las especialidades derivadas de la organización propia de las Comunidades Autónomas; legislación sobre expropiación forzosa; legislación básica sobre contratos y concesiones administrativas y el sistema de responsabilidad de todas las Administraciones públicas.» 
equilibrio o de superávit, computada en términos de capacidad de financiación de acuerdo con la definición contenida en el Sistema Europeo de Cuentas Nacionales y Regionales, y en las condiciones establecidas para cada una de las Administraciones públicas».

La filosofía jurídica de la ley se completaba, además, con el establecimiento del principio de eficiencia en la asignación y utilización de recursos públicos en el artículo 6 y la responsabilidad financiera derivada del incumplimiento de los compromisos adquiridos por España ante la Unión Europea en materia de estabilidad presupuestaria en su artículo 11. La Ley, por lo tanto, anticipaba las líneas maestras de lo que con posterioridad sería establecido en la Ley Orgánica de Estabilidad Presupuestaria y Sostenibilidad Financiera ${ }^{27}$.

Con carácter complementario a la Ley General de Estabilidad Presupuestaria se promulgó la Ley Orgánica 5/2001, de 13 de diciembre, complementaria a la Ley General de Estabilidad Presupuestaria ${ }^{28}$. Una ley nacida con el objeto de establecer, como señalaba su exposición de motivos, «mecanismos de coordinación entre la Hacienda Pública estatal y la de las Comunidades Autónomas en materia presupuestaria», aunque ambas leyes debieran aplicarse con carácter unitario. El objetivo último, por lo tanto, era comprometer a todas las Administraciones con la estabilidad presupuestaria, dejando, eso sí, autonomía para decidir, conforme al artículo 156.1 de la Constitución, los medios para alcanzarla.

En definitiva, el establecimiento de un riguroso marco jurídico en pro de la estabilidad presupuestaria hundía sus raíces en una filosofía económica sencilla pero históricamente de difícil cumplimiento: "el déficit o la deuda pública de boy son los impuestos de mañana» ${ }^{29}$.

27 Ley Orgánica 2/2012, de 27 de abril, de Estabilidad Presupuestaria y Sostenibilidad Financiera, promulgada como consecuencia de lo establecido en el artículo 135.5 de la Constitución.

28 La existencia de este doble marco legislativo, uno con carácter ordinario y otro con carácter orgánico lo explica Cano Bueso porque «la ordinaria se orienta al cumplimiento del principio de estabilidad mientras que la ley orgánica se destina al establecimiento de los instrumentos que garanticen la coordinación y cooperación entre Estado y Comunidades Autónomas para la prosecución de tal objetivo». CANO BUESO, Juan, «Dudas y certezas de las reforma constitucional española de 2011», Revista Española de la Función Consultiva, número 15, 2011, pág. 129.

29 Como señalaba Pascua Mateo con acierto, «me parece una política fiscal sensata la que tiende a eliminar el déficit presupuestario o, al menos, a reducirlo drásticamente en épocas de recesión, de modo que se compense fácilmente en las de expansión. Sin abundar en argumentos económicos acerca de las bondades de la disciplina presupuestaria (corrección de la inflación; credibilidad de una divisa, el euro, aún necesitada de cierto mimo y cuidado, como todo recién nacido; refuerzo de las oportunidades de actuación de un sector privado que no ha de competir con un Estado siempre con mayor credibilidad, por razones obvias de tamaño, a la bora de captar aborro privado), sí hay uno basado en el sentido común que siempre debe estar presente en las políticas públicas: como se ha dicho en no pocas ocasiones, el déficit o la deuda pública de boy son los impuestos 
Posteriormente, y en un contexto económico más propicio para la economía española, el Gobierno posterior decidió, en 2006, mediante la Ley 15/2006, de 26 de mayo, de reforma de la Ley 18/2001, de 12 de diciembre, General de Estabilidad Presupuestaria, modificar la legislación vigente en materia de estabilidad presupuestaria al entender que "Las Leyes vigentes aplican el principio de estabilidad con rigidez, independientemente de la situación económica, de modo que no sólo se pierde capacidad para combatir el ciclo, sino que incluso podían llevarse a cabo políticas de carácter procíclico. Si bien el equilibrio en las cuentas públicas es un elemento esencial de una política económica sostenible en el tiempo, debe instrumentarse adaptándolo a la situación cíclica de la economía para suavizar sus oscilaciones».

Una ley que, al igual que la que reformaba, se vio complementada con otra ley orgánica de modificación de la Ley Orgánica 5/2001, de 13 de diciembre, para adecuar la entonces vigente al nuevo marco reformado para las Comunidades Autónomas. Esta nueva ley orgánica era la Ley Orgánica 3/2006, de 26 de mayo, de reforma de la Ley Orgánica 5/2001, de 13 de diciembre, complementaria de la Ley General de Estabilidad Presupuestaria.

Por último, en virtud del Real Decreto Legislativo 2/2007, de 28 de diciembre, por el que se aprueba el texto refundido de la Ley General de Estabilidad Presupuestaria, fue derogada la Ley 18/2001, de 12 de diciembre, General de Estabilidad Presupuestaria y la Ley 15/2006, de 26 de mayo, de reforma de la Ley $18 / 2001^{30}$.

\subsection{La sentencia del Tribunal Constitucional de 20 de julio de 2011}

Pese a la aparente bondad de la norma, algunas comunidades, como Cataluña, consideraron que interfería en su autonomía presupuestaria, consagrada en

de mañana». PASCUA MATEO, Fabio, «Las nuevas leyes de Estabilidad Presupuestaria: aspectos formales y materiales», Revista de Administración Pública, número 158, 2002, págs. 182-183.

30 Como señalaba el Real Decreto Legislativo en su exposición de motivos, «La disposición final primera de la Ley 15/2006, de 26 de mayo, de reforma de la Ley 18/2001, de 12 de diciembre, General de Estabilidad Presupuestaria, autorizó al Gobierno para que, en el plazo de un año desde la entrada en vigor de la ley, refundiera en un solo texto dicha ley y la Ley 18/2001, de 12 de diciembre, General de Estabilidad Presupuestaria, regularizando, aclarando y armonizando las normas refundidas entre sí, asi como con lo dispuesto en la Ley Orgánica 5/2001, de 13 de diciembre, complementaria a la Ley General de Estabilidad Presupuestaria, en la Ley Orgánica 3/2006 de Reforma de aquélla, en la Ley Orgánica 8/1980, de 22 de septiembre, de Financiación de las Comunidades Autónomas, en la Ley 47/2003, de 26 de noviembre, General Presupuestaria, y en el Texto Refundido de la Ley Reguladora de las Haciendas Locales, aprobado por Real Decreto Legislativo 2/2004, de 5 de marzo». 
el artículo $156^{31}$ de la Constitución, estableciendo una injustificada limitación a su potestad autoorganizativa y de su autonomía financiera ${ }^{32}$.

Por ello, el Parlamento de Cataluña presentó un recurso de inconstitucionalidad contra determinados artículos de la Ley 18/2001, de 12 de diciembre, General de Estabilidad Presupuestaria y de la Ley Orgánica 5/2001, de 13 de diciembre, complementaria de la Ley General de Estabilidad Presupuestaria.

Para los recurrentes, los objetivos de la Unión Europea en materia de estabilidad presupuestaria, que sirven como argumento justificativo de las dos leyes recurridas, no son concordantes, ya que si el objetivo europeo es que la proporción entre el déficit público previsto o real y el producto interior bruto no sobrepase el 3\% del PIB, la Ley 18/2001 pretende suprimir en todo caso el déficit público previsto o real.

Por otro lado, sostenían los recurrentes, las leyes en cuestión excedían las competencias estatales previstas en el artículo 149 de la Constitución, concretamente, en el 149.1.13, «Bases y coordinación de la planificación general de la actividad económica», restringiendo la autonomía política y financiera de las Comunidades Autónomas, recogida en los artículos 137 y 156.1 de la Constitución, y estableciendo además una superioridad jerárquica del Consejo de Política Fiscal y Financiera respecto del Parlamento de Cataluña que subvertía los principios fundamentales del Estado Autonómico.

31 Artículo 156 de la Constitución:

«1. Las Comunidades Autónomas gozarán de autonomía financiera para el desarrollo y ejecución de sus competencias con arreglo a los principios de coordinación con la Hacienda estatal y de solidaridad entre todos los españoles.

2. Las Comunidades Autónomas podrán actuar como delegados o colaboradores del Estado para la recaudación, la gestión y la liquidación de los recursos tributarios de aquél, de acuerdo con las leyes y los Estatutos,»

32 En relación con el sistema de financiación de las Comunidades Autónomas conviene recordar, como explica García Ruiz que «aunque la Constitución española de 1978 no perfiló un sistema acabado de financiación para las Comunidades Autónomas, fundamentalmente por la falta de un definitivo modelo de Estado, compensó ese carácter abierto con la remisión, en su art. 157.3, de la regulación de los mecanismos de financiación autonómica a una ley orgánica (...). A esta reserva de ley orgánica se dio cumplimiento desde fechas relativamente tempranas mediante la Ley Orgánica 8/1980, de 22 de septiembre, de Financiación de las Comunidades Autónomas, conocida como la LOFCA (...). Esta ley orgánica, esto es, la LOFCA viene a representar en nuestro ordenamiento jurídico el papel de una auténtica constitución financiera, con la matización de que no es una fuente del derecho atributiva de recursos financieros, ya que éstos ya han sido conferidos directamente por el artículo 157.1 CE, sino una norma que delimita y concreta la clase de competencia que tienen las Comunidades Autónomas en relación con su sistema de ingresos». GARCÍA RUIZ, José Luis, «La Financiación Autonómica: ¿competencia constitucional o estatutaria?». Revista Española de Derecho Constitucional, núm. 75, 2005, pág. 35. 
Se vulneraba también para los recurrentes la autonomía local y las competencias de la Generalitat en materia de tutela financiera de los Entes Locales, reputándose inconstitucional la fijación del objetivo de estabilidad presupuestaria en el ámbito local.

El 20 de julio de 2011 el Tribunal Constitucional dictó sentencia, desestimando el recurso, señalando, en referencia expresa a la estabilidad presupuestaria, que "la definición de estabilidad presupuestaria se configura como una orientación de política económica general que el Estado puede dictar ex art. 149.1.13, aunque su ejercicio haya de respetar la autonomía política y financiera de las Comunidades Autónomas», recordando además que, referido al establecimiento de límites presupuestarios, "nada cabe objetar desde el punto de vista competencial a que el Estado adopte esta decisión en la Ley de Presupuestos, máxime cuando ésta, lejos de ceñirse a ser un mero conjunto de previsiones contables, opera como un vebiculo de dirección y orientación de la política económica que corresponde al Gobierno». Un objetivo de estabilidad presupuestaria que, como señala el Tribunal más adelante, «se proyecta sobre el triple nivel territorial de nuestro ordenamiento: estatal, autonómico y local».

Reforzó el planteamiento recordando lo establecido en la STC 62/2001, donde se señala que "con base en el principio de coordinación delimitado por la LOFCA cabe, pues, justificar que el Estado acuerde una medida unilateral con fuerza normativa general susceptible de incidir en las competencias autonómicas en materia presupuestaria, siempre que aquélla tenga una relación directa con los mencionados objetivos de política económica», especificando, para la elaboración de los presupuestos, que "la legitimidad constitucional de que el Estado, ex arts. 149.1 .13 y 156.1 en conexión con el artículo 149.1.14 CE, establezca topes máximos en materias concretas a las Comunidades Autónomas en la elaboración de sus presupuestos se extiende, con igual fundamento, a la fijación de topes generales para dichos presupuestos, toda vez que la política presupuestaria es un instrumento de la política económica de especial relevancia, a cuyo través incumbe al Estado garantizar el equilibrio económico general».

El Tribunal pone de relieve, además, que el Consejo de Política Fiscal y Financiera, lejos de ser, como exponían los recurrentes, un órgano atentatorio de la autonomía política y financiera de la Generalitat por la fijación del objetivo de estabilidad presupuestaria, realiza dicha función, como señala la STC 31/2010, "con carácter general y de forma homogénea para todo el sistema», no quebrando la autonomía política de la Generalitat en su ámbito competencial ni tampoco su suficiencia financiera ni la autonomía de gasto. La Generalitat podrá elaborar sus presupuestos con total autonomía, pero deberá respetar el objetivo de estabilidad fijado por el Consejo.

Por lo tanto, la autonomía financiera y presupuestaria de las Comunidades Autónomas no es total, aunque no encuentre tutela estatal, sino que debe 
estar coordinada con el Estado al objeto de armonizar el sistema y establecer, adaptados a las políticas que se implementen en las respectivas Comunidades Autónomas, un objetivo común de estabilidad presupuestaria y equilibrio financiero.

Lo oportuno de esta sentencia, a escasas cinco semanas del acuerdo de reforma constitucional, permitió alejar todo atisbo de duda subyacente acerca de la obligatoriedad de todas las Comunidades Autónomas, coordinadas por el Estado, de cumplir con el objetivo de reducción del déficit público.

\section{EL PROCESO DE REFORMA}

\subsection{El Acuerdo Político PP-PSOE y la Proposición de Ley de Reforma}

Los partidos políticos promotores de la reforma constitucional, PP y PSOE, se comprometieron en un acuerdo político ${ }^{33}$ firmado en la madrugada del 25 de agosto — tan sólo dos días después del anuncio hecho en el Pleno por el Presidente del Gobierno-, a desarrollar mediante ley orgánica, antes de que finalizase el primer semestre del año 2012, y fuese quien fuese el vencedor de la próxima contienda electoral, prevista para el 20 de noviembre, lo recogido en

33 El texto del acuerdo es el siguiente:

"El PSOE y el PP entienden que es oportuno en este momento político sentar ya las bases de un acuerdo sobre la Ley Orgánica a que se refiere el artículo 135 de la C.E., que debe ser aprobada con urgencia antes del 30 de junio de 2012.

Esta Ley Orgánica fijará en un 0,4 por ciento el déficit estructural global máximo del conjunto de las Administraciones Públicas a partir de 2020, que se distribuirá del siguiente modo:

- El déficit estructural en que podrá incurrir el Estado no superará el 0,26 por ciento del producto interior bruto nacional.

- El déficit estructural en que podrá incurrir cada Comunidad Autónoma no podrá superar el 0,14 por ciento de su producto interior bruto.

- Las entidades locales deberán presentar equilibrio presupuestario.

La Ley Orgánica establecerá los criterios para la reducción progresiva del nivel de deuda, de acuerdo con el valor de referencia establecido en el Tratado de Funcionamiento de la Unión Europea, con el objetivo de alcanzar en 2020 el límite contemplado en el artículo 135.

Los límites referidos al déficit estructural, así como la senda para la consecución del objetivo de deuda en 2020, podrán ser objeto de revisión en 2015 y en 2018, a iniciativa de cualquiera de las partes que suscriben este acuerdo.

A los efectos del contenido de la citada Ley Orgánica, se entenderá por saldo estructural aquel que se deriva de no considerar los ingresos y gastos públicos relacionados con las expansiones y recesiones normales de los ciclos económicos, garantizando así la sostenibilidad a largo plazo de los servicios públicos fundamentales. » 
la reforma del artículo 135 de la Constitución. Dicho acuerdo fue pactado en paralelo a la Proposición de Ley de reforma del artículo 135 de la Constitución que presentarían al día siguiente, 26 de agosto, ambos Grupos.

Como se señalaba en la exposición de motivos, la reforma del artículo 135 perseguía tres claros objetivos: "garantizar el principio de estabilidad presupuestaria, vinculando a todas las Administraciones Públicas en su consecución, reforzar el compromiso de España con la Unión Europea y, al mismo tiempo, garantizar la sostenibilidad económica y social de nuestro país».

Para la portavoz del Grupo Parlamentario Popular, Soraya Saénz de Santamaría, "este compromiso de estabilidad presupuestaria ba de suponer un avance para la confianza en la economía española, y la base para abordar las reformas que necesita para su recuperación», sobre un texto que "garantice la sostenibilidad de nuestro Estado de bienestar y el mantenimiento de los derechos sociales, gracias a un principio de estabilidad presupuestaria», mientras que para la diputada socialista Elena Valenciano, Secretaria de Política Internacional y Cooperación del PSOE, la reforma pretendía "garantizar el futuro y la estabilidad en las cuentas y enviar un mensaje que dé seguridad y garantías a aquellos que tienen que ayudar».

Así, el compromiso, de hondo calado político, pretendía sustraer a la dinámica política de las Administraciones Públicas, caracterizadas por continuos cambios, un asunto capital para la credibilidad internacional de un país: la estabilidad presupuestaria. Asunto novedoso en su formulación constitucional, ya que tan sólo dos países de entre nuestros socios europeos, Alemania y Polonia, la habían consagrado en sus respectivos textos constitucionales ${ }^{34}$.

34 Como explica Tajadura, «En el marco del programa político de la Gran Coalición entre el SPD y la CDU, la Constitución alemana estableció en 2009, como regla general, que - a partir del año 2016-el déficit presupuestario no podrá ser nunca superior al 0,35\% del PIB. A los Estados federados les quedará probibido pedir créditos a partir de 2020. La Ley Fundamental prevé, sin embargo, que el Gobierno y los Estados puedan endeudarse más de lo previsto en situaciones de emergencia. Si sufren, por ejemplo, desastres naturales o crisis financieras graves. En tales casos, los Gobiernos tendrán que disponer planes concretos para devolver esos créditos en «plazos adecuados». Además, Alemania creó en 2009 un Consejo de Estabilidad para vigilar las cuentas federales y las de los Estados». TAJADURA TEJADA, Javier, «Reforma Constitucional e integración europea». Claves de Razón Práctica, número 216, octubre 2011, pág. 22. En el caso polaco, como expone Cano, «la Constitución de 2 de abril de 1997 establece que no será admisible la contratación de préstamos, avales y garantías financieras que dieren lugar a una deuda pública nacional superior a tres quintas partes del valor del Producto Interior Bruto anual. El método para calcular el valor del PIB anual y la deuda pública nacional serán especificados por la ley (art. 216.5). El precepto dedicado a las cuestiones financieras del Estado limita la acción del Gobierno que viene condicionada por la exigencia de una ley para regular las finanzas públicas dentro de las probibiciones concretas que la suprema norma establece». CANO BUESO, Juan, op. cit., pág. 125. 
Una estabilidad presupuestaria que, como se recogía en la propia exposición de motivos de la Proposición de Ley de reforma presentada, "adquiere un valor verdaderamente estructural y condicionante de la capacidad de actuación del Estado, del mantenimiento y desarrollo del Estado Social que proclama el artículo 1.1 de la propia Ley Fundamental y, en definitiva, de la prosperidad presente y futura de los ciudadanos. Un valor, pues, que justifica su consagración constitucional, con el efecto de limitar y orientar, con el mayor rango normativo, la actuación de los poderes públicos».

La reforma recogía el tenor de lo establecido en el Pacto de Estabilidad y Crecimiento de la Unión Europea ${ }^{35}$, teniendo como fundamentos jurídicos los artículos 121 y 126 del Tratado de Funcionamiento de la Unión Europea, que consagraban la disciplina fiscal ${ }^{36}$.

Como consecuencia de ello, el nuevo Gobierno presentó la Ley Orgánica de desarrollo del nuevo artículo 135 de la Constitución en el primer trimestre del año, siendo su anteproyecto remitido a las Cortes a mediados de marzo, para ser aprobado a finales de abril y entrar en vigor el uno de mayo. Dicho anteproyecto modificó algunos parámetros con respecto a lo acordado en el Acuerdo Político, lo que propició la inmediata reacción del PSOE al considerar que se estaba vulnerando lo acordado, introduciendo modificaciones importantes que afectaban al núcleo esencial de lo propuesto.

35 El Pacto de Estabilidad y Crecimiento, como es sabido, es un compromiso de índole fiscal de los países miembros de la Unión, con objeto de consolidar la Unión Económica y Monetaria europea. El Pacto implica la verificación y control de las finanzas de los países miembros y un régimen sancionador en caso de incumplimiento. Se remonta a 1997, previo a la adopción como moneda del euro, como mecanismo de garantía del cumplimiento de las mismas condiciones que se habían requerido para entrar en la moneda única.

36 Poco después de la reforma, la Directiva 2011/85, de 8 de noviembre (DOUE 23 de noviembre), sobre los requisitos aplicables a los marcos presupuestarios de los Estados miembros, consagró en la elaboración de los presupuestos unos principios tendentes a cumplir los objetivos de déficit público, estableciendo un marco de obligado cumplimiento más allá de la consagración constitucional de la estabilidad presupuestaria. Como señala la directiva, a modo explicativo, en su párrafo primero, "Es necesario tomar como base la experiencia adquirida en el trascurso del primer decenio de la unión económica y monetaria. La reciente evolución económica ba planteado nuevos desafíos al ejercicio de la política presupuestaria en toda la Unión y, en concreto, ha puesto de relieve la necesidad de reforzar la responsabilización nacional y de disponer de unos requisitos uniformes con respecto a las normas y los procedimientos que configuran los marcos presupuestarios de los Estados miembros. En concreto, debe precisarse lo que deben hacer las autoridades nacionales para cumplir las disposiciones del Protocolo ( $\left.{ }^{\circ}{ }^{\circ} 12\right)$ sobre el procedimiento aplicable en caso de déficit excesivo, anejo al Tratado de la Unión Europea (TUE) y al Tratado de Funcionamiento de la Unión Europea (TFUE) y, en particular, su artículo 3». 
Así, si bien el Acuerdo inicial establecía que el déficit estructural sería del $0,4 \%$, en el anteproyecto de Ley Orgánica se suprimió dicho porcentaje, siendo situado en el $0 \%$, es decir, «no déficit», tal y como se contenía en la Ley General de Estabilidad Presupuestaria de 2001.

Frente a críticas más o menos interesadas e ideologizadas, el fondo del acuerdo es loable, porque deja a los gobiernos — sean estos el Central, las comunidades autónomas o las corporaciones locales- la concreción presupuestaria según su discrecionalidad política, pero les obliga, sea cual fuere la coyuntura en la que se encuentre la economía nacional, a un compromiso de rigor en la gestión de las cuentas públicas para alejar futuras crisis o, al menos, amortiguar su impacto sobre la economía del Estado. Es en esto en donde radica el éxito y el sentido de la reforma constitucional para constitucionalizar el llamado «techo de gasto» y desarrollar el precepto constitucional modificado mediante una Ley Orgánica de Estabilidad Presupuestaria y Sostenibilidad Financiera que implique en forma y fondo a todas las Administraciones Públicas.

\subsection{El procedimiento parlamentario}

Los partidos políticos promotores de la reforma presentaron, a través de sus Grupos parlamentarios, el Popular y el Socialista, la Proposición de Ley de reforma de la Constitución el 26 de agosto de 2011.

Una vez presentada, la iniciativa de reforma constitucional, tal y como se establece en el artículo 166 de la Constitución, «se ejercerá en los términos previstos en los apartados 1 y 2 del artículo $87 »^{37}$.

En el caso concreto que nos ocupa, al ser la reforma constitucional operada una reforma parcial de la Constitución del artículo 167, no se requerían requisitos específicos en cuanto al procedimiento, a diferencia a lo que ocurre con la reforma agravada del artículo 168, donde los requisitos establecidos son, como es sabido, muy rigurosos.

37 Artículo 87.1 y 2 de la Constitución:

"1. La iniciativa legislativa corresponde al Gobierno, al Congreso y al Senado, de acuerdo con la Constitución y los Reglamentos de las Cámaras.

2. Las Asambleas de las Comunidades Autónomas podrán solicitar del Gobierno la adopción de un proyecto de ley o remitir a la Mesa del Congreso una proposición de ley, delegando ante dicha Cámara un máximo de tres miembros de la Asamblea encargados de su defensa.» 
En lo que respecta al trámite parlamentario, se inició en el Congreso, aunque, con idéntico resultado y tal y como establece en los artículos 152 y 153 de su Reglamento, podría haberse iniciado en el Senado ${ }^{38}$.

En el Congreso, conforme a lo establecido en el artículo 146 de su Reglamento ${ }^{39}$, la reforma constitucional sería tramitada como un proyecto o proposición de ley cualquiera, aunque dada la particularidad de consistir en una reforma parcial de la Constitución, la reforma requería la firma de dos Grupos parlamentarios o una quinta parte de los diputados, lo que se lograba en ambos supuestos al contar con el apoyo del Partido Popular y el Partido Socialista, proponentes de la reforma.

Dichos Grupos, además, solicitaron su tramitación por el procedimiento de urgencia y su aprobación en lectura única, que fue concedida por la Mesa del Congreso oída la Junta de Portavoces el día 30 de agosto, cuatro días después de su presentación conjunta el 26 de septiembre.

En cualquier caso, y pese a su especificidad, la primera fase de la reforma constitucional requirió de la toma en consideración parlamentaria en el Congreso donde, pese a un agrio debate, se superó el trámite el treinta de agosto con 318 votos a favor (PSOE, PP y UPN), 16 en contra (PNV, ERC-IU-ICV, BNG, UPyD, Nafarroa Bai y un diputado del PSOE) y dos abstenciones, co-

38 Artículo 152 del Reglamento del Senado:

«Cincuenta Senadores que no pertenezcan a un mismo Grupo parlamentario podrán presentar proposiciones articuladas de reforma constitucional.»

Artículo 153 del Reglamento del Senado:

«Presentada una proposición de ley de reforma constitucional será sometida al trámite de toma en consideración conforme a lo previsto en el artículo 108. En todo caso, los plazos y el número y duración de los turnos de palabra serán los que determine el Presidente, de acuerdo con la Mesa y oída la Junta de Portavoces.»

39 Artículo 146 del Reglamento del Congreso:

«1. Los proyectos y proposiciones de reforma constitucional a que se refieren los artículos 166 y 167 de la Constitución, se tramitarán conforme a las normas establecidas en este Reglamento para los proyectos y proposiciones de ley, si bien éstas deberán ir suscritas por dos Grupos Parlamentarios o por una quinta parte de los Diputados.

2. El texto aprobado por el Pleno deberá someterse a una votación final en la que, parar quedar aprobado, se requerirá el voto favorable de los tres quintos de los miembros de la Cámara.

3. Si no bubiere acuerdo entre el Congreso de los Diputados y el Senado, se intentará obtenerlo por medio de una Comisión Mixta paritaria. Si ésta llegase a un acuerdo, el texto resultante será sometido a votación, en la que debe obtener la mayoría señalada en el apartado precedente.

4. De no lograrse la aprobación mediante el procedimiento del apartado anterior, y siempre que el texto hubiere obtenido el voto favorable de la mayoría absoluta del Senado, el Congreso, por mayoría de dos tercios, podrá aprobar la reforma». 
rrespondientes a Coalición Canaria. Los Grupos Catalán (Convergència i Unió) y Vasco (Partido Nacionalista Vasco) decidieron no votar al considerarse excluidos e ignorados en el proceso de acuerdo y reforma entre los dos grandes partidos.

Las posiciones de los Grupos parlamentarios se reflejaron en este debate de forma muy enconada, revelando profundas discrepancias no solo con la forma adoptada para el objetivo pretendido, sino con el trasfondo ideológico que, a tenor de algunos, se contenía de forma implícita en la reforma constitucional.

Así, si mientras para el portavoz socialista, José Antonio Alonso, la reforma tenía como objetivo "llevar el principio de estabilidad a la Constitución para fortalecer la confianza en la economía española y, consecuentemente, crear mayores condiciones objetivas para el crecimiento futuro», y para la portavoz popular, Soraya Saénz de Santamaría, "hacer de la austeridad una obligación política de todos los poderes públicos, de la estabilidad la base del crecimiento económico y del equilibrio presupuestario la certidumbre sobre la que se asiente la recuperación económica de nuestro país y la garantía del bienestar social», las críticas fueron durísimas por parte del resto de los Grupos parlamentarios.

Para el portavoz de Convergència i Unió, Josep Antoni Duran i Lleida, el acuerdo de reforma propuesto tanto por el Partido Socialista como el Partido Popular no había contado con el resto de los Grupos por lo que para CiU, que había participado en el proceso de elaboración de la Constitución, se había producido una «ruptura del proceso constituyente». Una ruptura tanto por razones de forma, al carecer del «sosiego y consenso», como de fondo porque, "limitar la autonomía financiera de las comunidades autónomas al incrementar el rango legal del principio de estabilidad presupuestaria va en contra del actual reconocimiento de autonomía financiera de la Constitución española».

Josu Erloreka, portavoz del Partido Nacionalista Vasco y opuesto también a la reforma constitucional planteada, argumentaba la negativa de su Grupo a apoyar la reforma sobre la base de que «el equilibrio presupuestario, prudentemente aplicado, contribuye a garantizar la sostenibilidad de las cuentas públicas, quién lo puede negar, pero constitucionalizarlo no porque, como toda regla general, la del equilibrio presupuestario también ha de conocer sus excepciones y la rigidez de la Carta Magna es incompatible con la flexibilidad y el buen sentido que ha de presidir la gestión de estas excepciones».

Otras críticas, más centradas en el aspecto «ideológico» de la reforma, las sostuvieron Joan Ridao, de Esquerra Republicana de Catalunya, para quien "de lo que se trata es de una simple imposición del Banco Central Europeo, de la señora Merkel, de la derecha europea, es el oneroso peaje que ustedes —ambos — están pagando a cambio del rescate de la deuda pública del mes de julio, a cambio del plácet alemán a la emisión de eurobonos»; o Gaspar Llamazares, de Izquierda Unida, quien también 
sostuvo que se había producido una ruptura del consenso constitucional porque "no se nos ha llamado ni se nos ha tenido en cuenta; se nos ha ninguneado», sosteniendo además la necesidad de un referéndum consultivo porque «no es una reforma parcial, afecta al título preliminar, a la soberanía del pueblo español, afecta al Estado democrático y social, afecta también al título I, afecta a los derechos sociales. Por lo tanto, se trata de una reforma dura y, como tal, hay que tratarla: hay que acordarla, hay que disolver la Cámara y hay que convocar un referéndum». Para Francisco Jorquera, portavoz del Bloque Nacionalista Galego, la reforma suponía «constitucionalizar uno de los principios ideológicos más duros del neoliberalismo» y sacrificar «la soberanía y el autogobierno».

Pese a las críticas, el apoyo de los Grupos proponentes garantizaba ampliamente $e^{40}$, su aprobación por una mayoría cualificada de tres quintos de ambas Cámaras que se establece en el artículo 167.1 de la Constitución y los artículos 146.2 del Reglamento del Congreso y el artículo 156.1 del Reglamento del Senado ${ }^{41}$. Una vez aprobada la toma en consideración, y aprobada la propuesta de la Mesa del Congreso de acordar su tramitación en lectura única, se estableció un brevísimo plazo de enmiendas, de apenas dos días, hasta el uno de septiembre, quedando fijada la aprobación y votación definitiva para el día siguiente, dos de septiembre.

Finalmente, tras el debate de totalidad de las enmiendas admitidas a trámite por la Mesa de la Cámara, la reforma fue aprobada en el Congreso de los Diputados el dos de septiembre por 316 votos a favor (Partido Popular, Partido Socialista y Unión del Pueblo Navarro), 5 votos en contra (Coalición Canaria,

40 La mayoría cualificada de tres quintos, 210 diputados en el caso del Congreso, se superaba con creces puesto que la suma de los diputados del Grupo Parlamentario Socialista y el Grupo Popular alcanzaba los 321 (169 del Grupo Socialista y 152 del Grupo Popular). En el caso del Senado también se superaba, al estar formado por 261 senadores y ser por tanto la mayoría de tres quintos 157 senadores, cifra que sumaban los Grupos Popular y Socialista.

41 Artículo 156 del Reglamento del Senado:

«1. La aprobación de la reforma constitucional requerivá la obtención de una mayoría favorable de tres quintos de Senadores en una votación final sobre el conjunto.

2. Si el Senado aprobase la reforma constitucional con el mismo texto recibido del Congreso de los Diputados se comunicará a esta última Cámara.

3. Cuando el texto aprobado por el Senado difiriese del aprobado previamente por el Congreso, la Cámara elegirá los Senadores que hayan de representarla en la Comisión Mixta paritaria encargada de elaborar un texto común, que será posteriormente votado por ambas Cámaras.

4. El texto elaborado por la Comisión a que se refiere el apartado anterior, deberá ser aprobado por una mayoría de tres quintos de Senadores. Si no se alcanzase dicho número, pero fuese votada favorablemente por la mayoría absoluta del Senado, el Presidente lo comunicará al del Congreso a los efectos previstos en el apartado segundo del artículo 167 de la Constitución.» 
Unión, Progreso y Democracia y dos del PSOE, uno del exsecretario general del sindicato Comisiones Obreras Antonio Gutiérrez y otro de un diputado balear popular por error), ninguna abstención y la negativa de los Grupos Catalán (Convergència i Unió) y Vasco (Partido Nacionalista Vasco) a votar.

Tras la aprobación en el Congreso, el trámite parlamentario de la reforma constitucional continuó en el Senado, donde el día seis de septiembre inició su breve andadura en la Comisión Constitucional, repitiéndose la argumentación del debate del Congreso. En la Comisión se rechazaron todas las enmiendas y se aceptó como Dictamen el texto remitido por el Congreso. No obstante, se presentaron cuatro votos particulares ${ }^{42}$.

Tras su aprobación en la Comisión Constitucional el día seis, la reforma fue aprobada por el Pleno al día siguiente, el siete de septiembre, con 233 votos a favor (PP, PSOE y UPN), tres en contra (los dos de Coalición Canaria y uno de Foro Asturias) y la negativa a votar de los Grupos Catalán y Vasco y la deliberada ausencia del Bloque Nacionalista Galego y Esquerra Republicana de Catalunya.

\subsection{El trámite de enmiendas en el Congreso y el Senado}

En lo referente al trámite de enmiendas, se presentaron en total veinticuatro en el Congreso ${ }^{43}$ y veintinueve en el Senado ${ }^{44}$. No obstante, el procedimiento adoptado para su reforma, duramente criticado por la totalidad de los Grupos que no intervinieron en la misma bien por su excesiva celeridad, bien por considerarse excluidos del proceso o por estar en desacuerdo con la misma, propició que se presentasen — como ya señalaron algunos portavoces en el debate de la toma en consideración-, propuestas de reforma constitucional alternativas a la presentada, en su mayoría no coincidentes con el objeto de la reforma

42 Los cuatro votos particulares fueron presentados por el Grupo Parlamentario Mixto (Coalición Canaria), el Grupo Parlamentario Catalán en el Senado de Convergència i Unió, el Grupo Parlamentario Entesa Catalana de Progrés y el Grupo Parlamentario de Senadores Nacionalistas (PNV y BNG).

43 En el Congreso, por Grupos, presentaron enmiendas CIU (8), Mixto (5 Unión, Progreso y Democracia, 2 Coalición Canaria, 2 Nafarroa Bai y 1 el Bloque Nacionalista Galego), Esquerra Republicana de Catalunya-Izquierda Unida-niciativa per Catalunya (4) y el PNV (2).

44 En el Senado, el mayor número de enmiendas lo presentó el Grupo Parlamentario de la Entesa Catalana de Progrés, con quince enmiendas, seguido del Grupo Catalán de Convergència i Unió, con ocho y el Grupo de Senadores Nacionalistas, con cuatro. Por último, Coalición Canaria, del Grupo Mixto, presentó dos. 
constitucional. Dichas enmiendas fueron rechazadas por las Mesas del Congreso y del Senado, y por lo tanto, no llegaron a ser defendidas por los portavoces de los Grupos que las presentaron.

La Mesa del Congreso inadmitió a trámite seis enmiendas al considerar que suponían una alteración del procedimiento de reforma constitucional contemplado en el Título X de la Constitución ${ }^{45}$, postulaban ${ }^{46}$ o requerían ${ }^{47}$ una reforma constitucional del artículo 168 o bien por una cuestión procedimental del orden material ${ }^{48}$.

El resto de las enmiendas, dieciocho, si fueron, en cambio, admitidas a trámite por la Mesa del Congreso y debatidas, pero fueron rechazadas en Pleno, sin excepción alguna. Tan solo se aceptó, a propuesta del Presidente del Congreso,

45 Es el caso de la enmienda número 1, de totalidad con texto alternativo, del Grupo Mixto (BNG) que, en su Disposición final única sometía a referéndum la reforma de los artículos 131 y 133 de la Constitución contemplada en su enmienda a la totalidad con texto alternativo; de la enmienda número 3, de adición. del Grupo Mixto (Nafarroa Bai) que proponía como nueva disposición transitoria primera la celebración de un referéndum el mismo día de las elecciones generales, el 20 de noviembre; o de la enmienda número 21, de adición, también del Grupo Mixto (UPyD), para someter a referéndum la reforma constitucional.

46 La enmienda número 4, de totalidad con texto alternativo, del Grupo Parlamentario de Esquerra Republicana de Catalunya-Izquierda Unida-Iniciativa per Catalunya-Verds planteaba una reforma de calado de la Constitución, del artículo 168, incluyendo reformas no sólo del Título VII objeto de la reforma, sino también del Título Preliminar (para abordar la forma política del Estado y definir el Estado como federal con reconocimiento de la plurinacionalidad), en el capítulo III del Título I (para introducir un mayor nivelo de garantía para la efectividad de los derechos al trabajo, la vivienda digna, la protección de la salud, el derecho a la educación y el derecho a disfrutar de un medio ambiente adecuado para el desarrollo de la persona), Título II, al capítulo I del Título III (constitucionalizar el derecho al sufragio activo de los españoles residentes en el exterior, la de los extranjeros residentes en España y la reforma del Senado con objeto de convertirlo en una Cámara de representación territorial), del Título VIII (en el sentido de la reforma federal del Estado), del Título IX (para garantizar la renovación del Tribunal Constitucional y reforzar su independencia) y del Título X (para establecer la obligatoriedad de la consulta mediante referéndum de cualquier modificación no técnica o metodológica de la Constitución).

47 Es el caso de la enmienda número 6, de adición, del Grupo Parlamentario de Esquerra Republicana de Catalunya-Izquierda Unida-Iniciativa per Catalunya-Verds, que proponía una modificación del artículo 2 de la Constitución, al que añadía una nueva disposición adicional para reconocer el derecho a la autodeterminación; o la número 11, del Grupo Parlamentario Vasco, con igual sentido.

48 Este es el caso de la enmienda número 5, de supresión, del Grupo Parlamentario de Esquerra Republicana de Catalunya-Izquierda Unida-Iniciativa per Catalunya-Verds, que es en realidad una enmienda a la totalidad de devolución de la propuesta de reforma constitucional, inadmisible de conformidad con el artículo 126.5 del Reglamento del Congreso. 
una enmienda que se podría calificar como de orden estético o gramatical en el párrafo tercero del artículo 135 propuesto en la reforma ${ }^{49}$.

La Mesa del Senado, al igual que en el Congreso, no admitió a trámite algunas enmiendas, concretamente cinco, cuatro presentadas por el Grupo Parlamentario Entesa Catalana de Progrés (PSC-ERC-ICV) y una del Grupo Parlamentario de Senadores Nacionalistas (PNV). La Mesa sostuvo en su negativa idénticos motivos a los sostenidos por la Mesa del Congreso, inadmitiendo bien por cuestiones de orden técnico-formal —una enmienda ya formulada en otra-, como procedimental, al proponerse en algunas enmiendas medidas de reforma que requerirían el procedimiento agravado de reforma contemplado en el artículo 168 de la Constitución. En conclusión, por lo tanto, fueron admitidas y debatidas veinticuatro enmiendas ${ }^{50}$.

El debate, siguiendo la tónica de lo ocurrido tanto en el Congreso como en la Comisión Constitucional del Senado, mostró la acritud de los Grupos minoritarios con respecto a la reforma constitucional planteada, repitiéndose las argumentaciones empleadas en la toma en consideración del Congreso, aunque el tono empleado resultó aún más adusto.

Así, destacaron las intervenciones del senador Bofill, de Entesa Catalana de Progrès, para quien la iniciativa venía "a remachar el clavo de la sentencia del Tribunal Constitucional contra el estatuto y la autonomía de Cataluña. Cataluña no cabe en la Constitución española. Los catalanes y catalanas nos tenemos que preparar para saltar el muro constitucional» o la del senador Pérez Bouza, del Grupo de Senadores Nacionalistas, que sostuvo que la iniciativa era "una auténtica chapuza, por cierto muy propia de este Estado centralista y chapucero que es el estado español y que lo tiene demostrado a lo largo de la historia».

Finalmente, y conforme al calendario de tramitación de la Proposición de Reforma del artículo 135 en el Senado, se produjo la aprobación por el Pleno el siete de septiembre sin introducir modificaciones al texto remitido por el Congreso, con lo que la reforma fue aprobada.

49 El Presidente del Congreso, José Bono, observó «que en el párrafo 3. del artículo 135.3 del contenido de la propuesta que abora va a someterse a votación se incluye una expresión que dice: "en relación al producto interior bruto del Estado". Comprobado el diccionario usual de la Real Academia y puesto en contacto con el director de la misma, el señor Blecua, ha contestado por escrito que se trata de una incorrección lingüística formal. Propongo que se diga, sin cambiar en absoluto el contenido ni el sentido de la propuesta: "en relación con el producto interior bruto" ".

50 De las veinticuatro enmiendas admitidas, once eran del Grupo Parlamentario de Entesa Catalana de Progrés, ocho del Grupo Catalán en el Senado de Convergència i Unió, tres del Grupo de Senadores Nacionalistas y dos de Coalición Canaria del Grupo Parlamentario Mixto. 
Por último, y tras pasar el trámite parlamentario en las Cámaras, procedía, conforme a lo establecido en el artículo 167.3 de la Constitución, abrir el periodo de quince días dentro de los cuales una décima parte de los diputados o senadores podrían solicitar la celebración de un referéndum para ratificar la reforma constitucional aprobada. El plazo, que concluía el 26 de septiembre, finalizó sin que se produjese solicitud alguna, por lo que la reforma fue publicada en el Boletín Oficial del Estado al día siguiente, el 27 de septiembre, quedando definitivamente promulgada.

\subsection{El recurso de amparo ante el Tribunal Constitucional de dos diputados del Grupo Parlamentario de ERC-IU-ICV}

A causa del procedimiento utilizado en su tramitación, de urgencia y en lectura única, los diputados Gaspar Llamazares y Nuria Buenaventura, del Grupo parlamentario de ERC-IU-ICV, presentaron un recurso de amparo ante el Tribunal Constitucional el 28 de septiembre al considerar vulneradas sus facultades como parlamentarios y estimar que se estaba conculcando el artículo 23.2 de la Constitución ${ }^{51}$.

Los recurrentes adujeron en su demanda de amparo que la reducción de los plazos para la presentación de las enmiendas y acelerar la reforma vulneraba el ius in officium, pero el Tribunal estimó ya en los antecedentes de hecho que no se había conculcado ya que, pese a la celeridad del proceso, "los Diputados han dispuesto del trámite de la toma en consideración, han podido presentar enmiendas, recurrir las decisiones de trámite de la Mesa de la Cámara y, por último,

51 En concreto, interpusieron recurso contra las siguientes resoluciones y acuerdos:

a) Contra la Resolución de la Mesa del Congreso de los Diputados, de 30 de agosto de 2011, por la que se dispone la tramitación de la proposición de reforma del art. 135 CE por el procedimiento de urgencia y la finalización del plazo para la interposición de enmiendas por parte de los Grupos Parlamentarios el día 1 de septiembre de 2011 a las catorce horas.

b) Contra el Acuerdo de la Mesa del Congreso de los Diputados, de 2 de septiembre de 2011, desestimatorio de la reconsideración de los acuerdos adoptados el 30 de agosto de 2011, solicitada por los recurrentes.

c) Contra el Acuerdo del Pleno del Congreso de los Diputados, de 30 de agosto de 2011, por el que se aprueba la toma en consideración y la tramitación por el procedimiento de lectura única de la proposición de reforma del art. $135 \mathrm{CE}$.

d) Contra el Acuerdo de la Mesa del Congreso de los Diputados, de 1 de septiembre de 2011, por el que se inadmite la enmienda a la totalidad con texto alternativo presentada por el Grupo Parlamentario al que pertenecen los recurrentes y su ulterior confirmación por acuerdo del mismo órgano rector de la Cámara, de 2 de septiembre de 2011. 
podrán manifestar su conformidad o rechazo a la reforma de la Constitución propuesta mediante el correspondiente voto».

Por otro lado, los recurrentes adujeron también que se había vulnerado el artículo 23.2 de la Constitución al considerar inadecuada la tramitación conforme al procedimiento establecido en el artículo 167. Estimaban que suponía una modificación no sólo del artículo 135, sino también, y de forma encubierta, del Título Preliminar, ya que la reforma establecía en su punto tercero que «los créditos para satisfacer los intereses y el capital de la deuda pública de las Administraciones se entenderán siempre incluidos en el estado de gastos de sus presupuestos y su pago gozará de prioridad absoluta», algo que para los recurrentes implicaba la introducción de un valor superior a los de justicia y equidad del Título Preliminar, con lo que el Estado se convertía en «rehén» de las condiciones que a la financiación pública estableciesen los mercados internacionales.

Sin embargo, en su fundamentación jurídica el Tribunal sostuvo, respecto a la pretensión de no considerar la reforma constitucional como ordinaria que «la Mesa del Congreso de los Diputados, con escrupulosa sujeción a lo dispuesto en los arts. 167 y 168 CE, únicamente podía calificar la reforma del art. 135 CE como objeto del procedimiento ordinario de reforma constitucional recogido en el art. 167 CE, sin plantearse eventuales conexiones del precepto objeto de la reforma con otros preceptos o apartados de la Norma Suprema que sí deban ser objeto del procedimiento agravado» (...) «Admitir la pretensión de los recurrentes alteraría el equilibrio buscado por el constituyente, corriendo el riesgo de dejar a la discreción del órgano rector de la Cámara la determinación del procedimiento de reforma constitucional».

Por último, y en lo referido al procedimiento de tramitación por lectura única y la declaración de urgencia, el Tribunal señala que "las normas aplicables (art.150 RCD y concordantes) no establecen materias vedadas a dicha tramitación, como sí sucede con el Reglamento parlamentario de alguna Asamblea autonómica. Pero es que, además, la adopción de dicho procedimiento no se ha debido a la voluntad de la Mesa del Congreso de los Diputados (que únicamente ba formulado propuesta en tal sentido según previene el artículo 150 RCD), como parece deducirse del escrito de reconsideración planteado por los recurrentes, sino al Pleno de la Cámara mediante la oportuna votación».

En suma, y como señalaba el Tribunal Constitucional en su Auto de inadmisión, para los demandantes «la utilización del procedimiento de reforma ordinario, además de inadecuada por razones materiales, supone una merma en las facultades de participación de los Diputados y de los propios ciudadanos por cuanto se eliminan las preceptivas convocatorias electoral y del referéndum previstas en el art. 168 CE». El recurso de amparo fue inadmitido a trámite el 13 de enero de 2012 al considerar 
el Tribunal que no existió ninguna vulneración de derecho fundamental. No obstante, tuvo tres votos particulares ${ }^{52}$.

\subsection{El polémico debate sobre la necesidad de un referéndum consultivo}

Un importante sector de la sociedad, para quien la reforma atacaba directamente al control del gasto público y, por lo tanto, limitaba las políticas de inversión pública que habían consolidado el Estado del Bienestar, planteó la necesidad de un referéndum consultivo para legitimar una reforma que, a juicio de algunos, carecía de honda legitimación social.

Ciertamente, toda reforma constitucional, en abstracto, no solo en el supuesto que nos ocupa, pudiera ser objeto de consulta popular, ya que el elenco de las materias a las que la Constitución obliga a promover un referéndum es un número mínimo, no un límite máximo y taxativo o numerus clausus.

No obstante, no resulta menos cierto que una reforma constitucional parcial o limitada, como la que se ha producido, por su propio contenido, carece de la relevancia política y social de una reforma agravada del artículo 168 que, por su trascendencia, requiere del referéndum para su validez.

$\mathrm{Y}$ eso, en puridad, debiera bastar para entender que, pese a la percepción general y los derechos sociales consolidados — algo discutido y discutible - un cambio de planteamiento económico que pudiera incluirse en la Constitución

52 Los de los magistrados Eugeni Gay Montalvo, Pablo Pérez Tremps y Luis Ignacio Ortega Álvarez. En el caso del magistrado Eugeni Gay su voto particular se fundamenta en que para la «adopción del procedimiento de lectura única, baste que así lo haya considerado el Pleno de la Cámara mediante oportuna votación» (...) «tratándose de una reforma de un texto constitucional que, como he dicho, se gestó como fruto de un delicado consenso pareciera que también hubiera motivos para entender que su naturaleza requería de una tramitación tal que facilitara la participación más plural posible, con la cual no se compadece el procedimiento de lectura única». Para el magistrado Pablo Pérez Tremps su discrepancia se fundamentaba en que «lo que en este caso se hace es inadmitir una demanda de amparo que, cumpliendo los requisitos procesales básicos, y poseyendo claramente trascendencia constitucional al tratarse de una demanda que afecta a una reforma de la Constitución, se entiende que no denuncia ninguna lesión susceptible de ser apreciada. Pero ello se produce, hay que insistir en ello, en un juicio liminar, icto oculi, sin tramitar el juicio de amparo de manera plena, y un juicio que da respuesta a una demanda suscitada por diputados, representantes de la nación española, que han participado en el procedimiento legislativo de reforma denunciando irregularidades en el mismo». Por último, para el magistrado Luis Ortega «bubiere sido más acorde con la función de control y tutela de la Constitución que este Tribunal tiene encomendada el haber establecido expresamente una reserva de conocimiento y examen del contenido de las reformas constitucionales realizadas, para evitar que, presentada la reforma de una parte de la Constitución a la que formalmente correspondería el procedimiento del artículo 167 CE, materialmente se estuviese produciendo también una variación sustancial de las partes de la Constitución cuya reforma exige adoptar el procedimiento del artículo 168 CE». 
para limitar el gasto — que, hay que recordar, no contiene limitación alguna, lo cual no quiere decir, a sensu contrario, que la Constitución permita o exija un gasto ilimitado — no constituye, por sí mismo, una restricción de la inversión en políticas sociales y, por lo tanto, de nuestro Estado del Bienestar, consagrado constitucionalmente, como es sabido, en el artículo uno de nuestra Carta Magna en la acepción de Estado social y democrático de Derecho ${ }^{53}$.

La argumentación de algunos sectores políticos y sociales, para quienes la reforma implicaba de forma indirecta una reforma de mayor calado, al modificar supuestamente el Título Preliminar no se sostiene, ya que la interpretación efectuada de la reforma constitucional se encuentra influida por un sesgo ideológico y no jurídico que, en su acepción más acusada, no sólo reniega de los principios que inspiran la modificación efectuada del artículo 135, sino de la más elemental ortodoxia presupuestaria.

En cualquier caso, y más allá de este tipo de debates, más políticos que jurídicos, la situación es, desde un punto de vista democrático-representativo, evidentemente paradójica puesto que, si bien los dos partidos proponentes de la reforma constitucional aglutinaban a más del noventa por ciento de los escaños en el Congreso ${ }^{54}$, en caso de haberse celebrado un referéndum consultivo sobre la reforma, ésta habría sido claramente rechazada por la grave crisis económica y el hastío ciudadano con la clase política.

\section{CONCLUSIONES: ¿ERA NECESARIA UNA REFORMA CONSTITUCIONAL?}

53 Pese a frecuentes equívocos en torno a la significación constitucional de la cláusula del Estado social, como señala Fernández-Miranda, «La cláusula jurídico-constitucional del Estado social está orientada a posibilitar la conquista del Estado de bienestar (o la sociedad de bienestar) pero ni lo garantiza ni podría garantizarlo. Más aún, ni siquiera existe un nexo de interdependencia necesaria entre ambos conceptos que pertenecen a órdenes de la realidad absolutamente distintos. Razonamiento que seguramente explica que los más intensos Estados de bienestar no incorporen en sus Constituciones la claúsula del Estado social». FERNÁNDEZ-MIRANDA CAMPOAMOR, Alfonso, «El Estado Social». Revista Española de Derecho Constitucional, número 69, 2003, pág. 180. Sobre este punto, y como señala Tajadura, "hay que recordar a los detractores de la reforma que uno de los principales responsables de los recortes sociales es precisamente el elevado endeudamiento público, que nos obliga a destinar al pago de intereses, cantidades cada vez mayores y que podrían ser destinadas a gastos sociales». TAJADURA TEJADA, Javier, op. cit., pág. 27.

54 Aun a riesgo de excesivo celo democrático, la suma de los Grupos Socialista y Popular en el Congreso en la pasada legislatura suponía el $91,71 \%$ de los escaños y el $83,81 \%$ de los votos obtenidos en las pasadas Elecciones Generales celebradas en marzo de 2008. 
Como señalábamos en la introducción, el anuncio de la reforma, inesperado para todo el arco parlamentario y la opinión pública en general, causó no poca extrañeza en gran parte de la sociedad española, que con razón se preguntaba cómo era posible que los dos principales partidos políticos fuesen incapaces de llegar a acuerdo alguno en los últimos siete años y, sin embargo, fuesen capaces de anunciar, gestar y dar a luz a una reforma constitucional en apenas tres semanas con un consenso asombroso.

Ciertamente, la extraordinaria gravedad de la actual coyuntura económica europea y, particularmente, española, obligó a adoptar medidas de hondo calado político y económico para tratar de salvaguardar la estabilidad financiera del país y su sostenibilidad futura, pero no es menos cierto que la reforma constitucional, por su trascendencia, requería de un ejercicio de profunda reflexión aún más sosegado del realizado y, sobre todo, más lento.

La Constitución —aun siendo obvio, es preciso recordarlo-, no es una norma sagrada inmaculada e irreformable ${ }^{55}$, pero tampoco es un cajón de sastre político del que se echa mano cuando se desea. Requiere de un amplísimo consenso que garantice la estabilidad más allá de gobiernos y políticas, pero también, sin duda, para alejar críticas que sólo sirven para alejar a la sociedad de la Norma Fundamental.

La reforma constitucional ha hecho, pues, de la necesidad, virtud, pero la vía procesal adoptada no puede calificada, en puridad, de virtuosa ${ }^{56}$, sino fruto de la celeridad que requerían unos tiempos y unas difíciles circunstancias.

Sin embargo, pese a que la reciente reformada operada por los dos partidos mayoritarios de forma exprés parece estar informada por esta tesis, que desconoce en la práctica las profundas imbricaciones que una reforma constitucional implica, no menos cierto resulta que la reforma constitucional era necesaria para consagrar un principio capital que ha sido obviado por sucesivos gobiernos españoles y europeos: la gestión rigurosa de las cuentas públicas más allá

55 En ese sentido, y como gráficamente expone López Aguilar en el título de un estudio sobre la reforma, hemos pasado de la Constitución irreformable a la reforma constitucional exprés. LÓPEZ AGUILAR, Juan Fernando, «De la Constitución »irreformable» a la reforma constitucional «exprés». Teoría y Realidad Constitucional, núm. 29, 2012, pág. 199.

56 Como señala Gavara de Cara, «aunque formalmente sea correcto, esta reforma por lo menos ha sido maltratada procedimentalmente, su consideración como un caso de extraordinaria y urgente necesidad, criterio materialmente discutible en todo caso y cuestionable en la eficacia de su resultado, ha ocasionado que el tipo de discusión sea más próximo a un decreto-ley que a un diálogo sereno entre las fuerzas políticas y la sociedad propia de una solemne trascendencia constitucional». GAVARA DE CARA, Juan Carlos, «Encuesta sobre la reforma de la Constitución». Teoría y Realidad Constitucional, número 29, 2012, pág. 74. 
de gobiernos e ideologías a través de la consagración jurídica del principio de estabilidad presupuestaria.

Un principio que, pese a dimanar del Derecho Comunitario, carecía en la práctica de efectividad para garantizar su cumplimiento ${ }^{57}$, por lo que, en un contexto de grave recesión europea — tras tres intervenciones en Grecia, Irlanda y Portugal_-, y la amenaza de extensión de la crisis de deuda a nuestro país, exigió de la adopción de extraordinarias medidas para alejar la amenaza de intervención y otorgar un mensaje de credibilidad y confianza no sólo a nuestros acreedores, sino también a nuestros socios europeos y a la sociedad española.

La consagración en nuestra Constitución, sin embargo, no tiene, pese al contexto de gestación de la reforma, un carácter meramente contingente o coyuntural, sino estructural, debiendo entenderse el principio de estabilidad presupuestaria como sinónimo de gestión eficiente de recursos públicos.

La gestión eficiente no es patrimonio ideológico de nadie, de ahí el sentido de su plasmación constitucional —su carácter neutro, si se quiere- pero su reclamo es una exigencia compartida por la sociedad y sus ciudadanos. Por ello, y pese a que algunos autores han dudado de la necesidad de la reforma ${ }^{58}$, y incluso de los cambios que supone ${ }^{59}$, la filosofía que subyace a la misma, lejos de ser una

57 En ese sentido, y como señala García-Andrade explicando las regulaciones comunitarias «si bien estableció reglas precisas que obligaban a los Estados a conducirse bajo el principio de la estabilidad presupuestaria desde la aprobación del Tratado de Maastricht, lo cierto es que aquellas disposiciones han presentado notables insuficiencias tanto formales — para lograr su efectividad - como materiales para lograr el objetivo buscado de estabilidad presupuestaria en una zona monetaria única». GARCÍA-ANDRADE GÓMEZ, Jorge, «La reforma del artículo 135 de la Constitución Española». Revista de Administración Pública, número 187, pág. 38.

58 Señala Blanco Valdés que «ni es necesario que el principio de estabilidad presupuestaria figure en la norma constitucional, como no figura a día de hoy en la mayor parte de las Constituciones europeas; ni, de figurar, es conveniente que la Constitución, dada su rigidez formal, lo regule con tal lujo de detalles que pueda acabar por ser un problema en lugar de una ventaja; ni, en fin, se justifica la urgencia de la reforma, vistos los plazos previstos en ella para su entra en vigor y efectiva aplicación». BLANCO VALDÉS, Roberto L., «Un disparate jurídico y político». Diario ABC, 27 de agosto de 2012.

59 Para algún autor, «Lo que desde puntos de partida jurídicos exclusivamente formales puede decirse en primer lugar es que nada sustancial o radicalmente decisivo ha cambiado en el panorama jurídico por el nuevo art. 135 CE. Para llegar a esta conclusión hay que tener en cuenta que unas cifras máximas de porcentajes de déficit y deuda pública sobre el PIB estaban ya establecidas en la normativa europea desde el momento en que se imagina la moneda única y se regula el llamado Pacto de Estabilidad y Crecimiento en 1997 — junto con otras normas auxiliares del mismo-, teniendo ello plasmación, finalmente, de una forma abstracta en el art. 126 TFUE abora vigente y que se concreta en el art. 1 del Protocolo sobre el procedimiento aplicable en caso de déficit excesivo (en la redacción resultante del Tratado de Lisboa) en el que aparecen las cifras de $3 \%$ en lo referente a la proporción entre el déficit público previsto o real y el PIB a precios de mercado y del $60 \%$ en lo referente a la proporción entre la deuda pública y el PIB a precios de mercado». EMBID IRUJO, Antonio, La Constitucionalización de la crisis económica. Editorial Iustel, Madrid, «012, págs. 79-80. 
cuestión ideológica, reviste el carácter necesario de una nueva forma de gestión orientada a la gobernanza y a la rendición de cuentas.

Asimismo, resulta capital destacar el amparo realizado por el Tribunal Constitucional quien, mediante la sentencia 134/2011, de 20 de julio, ha declarado constitucional la potestad del Estado para limitar el déficit de las comunidades autónomas, verdadero caballo de batalla en la lucha contra el déficit. Una sentencia de importancia trascendental, ya que contar con esa garantía jurídica, que en puridad pudiera entrar en colisión con la autonomía financiera de las comunidades autónomas, ha supuesto un espaldarazo jurídico a la reforma constitucional ${ }^{60}$. Las comunidades están pues obligadas a cumplir con el límite máximo de déficit impuesto por el Gobierno.

Por todo ello, la virtud de la reforma consiste precisamente en su objetivo último: otorgar la pátina de constitucionalidad a la estabilidad presupuestaria y la sostenibilidad financiera del conjunto de las Administraciones Públicas para convertirlas en un principio rector de nuestro orden constitucional y jurídico y eliminar así de la praxis política futura todos aquellos perversos comportamientos en la gestión de los recursos públicos que, tomando como base la bonanza del ciclo económico, contribuyeron a ahondar los desequilibrios del sistema.

Pese a todo, no menos cierto es que el procedimiento de reforma del artículo 135 de la Constitución debiera haber sido mucho más pausado, reflexivo y consensuado, más allá del amplio acuerdo que representa el pacto entre las dos principales fuerzas políticas de nuestro arco parlamentario. Si la reforma constitucional pretendía sentar unas nuevas bases que suponen un punto de inflexión en los paradigmas hasta ahora vigentes en la política presupuestaria y en la planificación y ejecución de políticas de gasto público, la reforma debiera de haber contado con un apoyo aún mayor.

La responsabilidad política y social de la reforma operada, en cualquier caso, no sólo recae en los partidos políticos promotores — PSOE y PP—, sino muy probablemente también en todos aquellos que han pretendido ver en la misma la consagración a nivel constitucional de un modelo ideológico «neoliberal»

60 En este punto, la doctrina no es unánime, ya que, si bien para algunos permitió la reforma constitucional, para otros la hizo innecesaria. Como expone Manuel Aragón, "una vez declarado por el Tribunal Constitucional (en reiterada jurisprudencia, por último en la STC 134/2011, de 20 de julio) que el Estado tiene competencia, según el artículo 149.1.13 y 14 CE, para dictar medidas de obligatorio cumplimiento que limiten global o parcialmente la capacidad presupuestaria, tanto de las corporaciones locales como de los gobiernos y parlamentos autonómicos, y sometan a autorización previa estatal la emisión de deuda por esas entidades públicas, el título de intervención ya existía sin necesidad de expresarse de manera concreta en el texto constitucional». ARAGÓN REYES, Manuel, «La reforma del artículo 135 CE» (cuestionario). Revista Española de Derecho Constitucional, núm. 93, 2011, pág. 169. 
—que según sus detractores, constituye la causa de la crisis económica—, o un ataque a la potestad autoorganizativa de las comunidades autónomas o a su autonomía financiera - algo que, como se ha expuesto con anterioridad en el análisis de la STC 134/2011, resulta falso_-, en vez de un nuevo marco jurídico para asegurar la prestación de los servicios públicos en un contexto de recesión económica y escasos recursos y garantizar así, desde otros paradigmas, la sostenibilidad de nuestro Estado del Bienestar.

En ese sentido, resulta aventurado e incluso peligroso juzgar, dos años después, la reforma constitucional del artículo 135. Es fácil caer en el prejuicio cognitivo de juzgar el pasado con los datos del presente, o incluso caer en el ejercicio ucrónico de reconstruir la historia a partir de lo que no fue, pero lo cierto es que dicha reforma, unida a su normativa de desarrollo - particularmente, la Ley Orgánica 2/2012, de 27 de abril, de Estabilidad Presupuestaria y Sostenibilidad Financiera-, «salvó» la situación en la que se encontraba nuestra economía, cerrando la espiral de desconfianza y miedo en nuestro futuro que se había instalado en nuestro país y en nuestros socios internacionales.

Por todo ello, la reforma constitucional ha cumplido los objetivos para los que fue diseñada, particularmente el primero de ellos y el más «intangible», la generación de confianza en nuestro país y credibilidad internacional en la solvencia de nuestra economía. Sólo por ello, y pese a las dudas que suscitó y sigue suscitando, la reforma constitucional del artículo 135 merece una valoración positiva.

Title:

THE RECENT CONSTITUTIONALIZATION OF THE BUDGETARY STABILITY: A NECESSARY REFORM

\section{Summary:}

1. Introduction. 2. Pomp and Circumstance of Reform Express. 3. Regulatory framework: 3.1 Constitutional framework. 3.2 Background: the General Law of budgetary stability in 2001. 3.3 The judgment of the Constitutional Court of 20 July 2011. 4. The process of reform: 4.1 The political agreement PP-PSOE and the proposition of law reform. 4.2 The parliamentary procedure. 4.3 The processing of amendments in Congress and Senate. 4.4 The appeal for Constitutional right's legal protection of two members of the parliamentary group ERC-IU-ICV. 4.5 The controversial debate on the need for a consultative referendum. 5. Conclusions: was a Constitutional Amendment Necessary? 


\section{Resumen:}

La reforma constitucional del artículo 135 de la Constitución, operada en septiembre de 2011 para introducir la estabilidad presupuestaria y la sostenibilidad financiera como principios fundamentales de nuestro ordenamiento, supuso un cambio de importancia trascendental en nuestro ordenamiento jurídico. Su implantación, consecuencia directa de la gravedad de la crisis económica y de la Unión Europea, fue objeto de una fuerte controversia jurídica a causa tanto de la celeridad con la que se tramitó, como por el motivo del que traía causa. Su incidencia e importancia es analizada en este artículo, estudiando sus causas, tramitación y necesidad.

\section{Abstract:}

The constitutional reform of article 135 of the Constitution operated in September 2011 to introduce stability budget and financial sustainability as fundamental principles of our legal system meant a change of transcendental importance in our legal system. Its implementation, a direct result of the gravity of the economic crisis and the European Union, was the subject of a strong legal controversy to cause both the speed with which is transacted, as for the reason that brought cause. Its incidence and importance is analyzed in this article, studying its causes, processing and need.

Palabras clave:

Reforma, Constitución, estabilidad, sostenibilidad, controversia.

Key words:

Reform, Constitution stability, sustainability, controversy. 
